\title{
Auderville (Manche) « Le Sémaphore », un amas de débitage côtier mésolithique
}

Auderville (Manche) "Le Sémaphore", Mesolithic Coastal Flint Knapping

Auderville (Manche) "Le sémaphore": ein lithisches Fundinventar mit bipolarer Abschlagstechnik aus dem Mesolithikum

Auderville (Manche) "El Semáforo", un grupo de talla costero mesolítico

\section{François Charraud et Gérard Vilgrain}

\section{OpenEdition}

Journals

Édition électronique

URL : http://journals.openedition.org/rao/2374

DOI : $10.4000 /$ rao.2374

ISBN : 978-2-7535-4053-8

ISSN : 1775-3732

\section{Éditeur}

Presses universitaires de Rennes

\section{Édition imprimée}

Date de publication : 15 décembre 2014

Pagination : 7-13

ISBN : 978-2-7535-4051-4

ISSN : 0767-709X

\section{Référence électronique}

François Charraud et Gérard Vilgrain, "Auderville (Manche) « Le Sémaphore », un amas de débitage côtier mésolithique », Revue archéologique de l'Ouest [En ligne], 31 | 2014, mis en ligne le 15 décembre 2016, consulté le 04 décembre 2020. URL : http://journals.openedition.org/rao/2374 ; DOI : https:// doi.org/10.4000/rao.2374 


\title{
Auderville (Manche) "Le Sémaphore », un amas de débitage côtier mésolithique
}

\author{
Auderville (Manche) "Le Sémaphore", Mesolithic Coastal Flint Knapping
}

\author{
François Charraud* \\ avec la collaboration de Gérard VILGRAIN**
}

\begin{abstract}
Résumé : Le site d'Auderville "le Sémaphore » a été découvert en 1990 lors de prospections menées par G. et J. Vilgrain (GRAC). Il a été fouillé en 2006 dans le cadre du PCR sur La Hague dirigé par C. Marcigny, car il était menacé de destruction à court terme (érosion littorale). Cette opération révèle un amas de débitage côtier de 2736 silex, dans un lambeau de sol de trois mètres carrés, épargné de l'érosion. Peu d'outils sont présents. Le débitage effectué sur des galets littoraux est peu investi techniquement. Ce site peut être interprété comme un poste de taille temporaire. Il documente les procédés d'acquisition et de transformation des ressources littorales. Le contexte de découverte, ainsi que quatre outils, suggèrent une attribution au Mésolithique.
\end{abstract}

\begin{abstract}
The site of Auderville "Semaphore" was discovered in 1990 during surveys conducted by G. and J. Vilgrain (GRAC). The excavation, carried out due to the site being threatened by coastal erosion, was associated to the PCR about La Hague directed by C. Marcigny. The excavation of a small strip of ground $\left(3 \mathrm{~m}^{2}\right)$ spared from erosion revealed an area of coastal flint knapping, containing 2736 flints with few tools. Flint knapping is performed on coastal raw materials and shows little technical investment. This site can be interpreted as a temporary settlement. It documents the acquisition and transformation processes of coastal resources. The context of discovery and typology of 4 tools, indicate the Mesolithic period.
\end{abstract}

Mots clés : Mésolithique, Normandie, Hague, débitage côtier.

Keywords: Mesolithic, Normandy, Hague, coastal flint knapping.

Auderville «Le Sémaphore » se situe en Basse-Normandie, à proximité du cap de la Hague (fig. 1). Il s'agit d'un promontoire granitique peu élevé (+ 5 mètres NGF) au-dessus du platier de la côte septentrionale de La Hague. Le substrat géologique est constitué de granites clairs à grains fins ou moyens (granite du cap de La Hague : Dupret, 2005). À marée haute, ce promontoire est complètement entouré par la mer : les quelques lambeaux de sol préservés à son sommet sont de ce fait fortement exposés aux éléments.
Les côtes nord et ouest de La Hague présentent un découpage relativement accidenté. Elles comportent une série d'écueils et de petits promontoires rocheux en tous points semblables à celui du Sémaphore. Depuis ces promontoires on domine le raz Blanchard et les îles Anglo-Normandes.

Le site a été découvert par G. et J. Vilgrain (GRAC) à l'occasion d'une érosion importante du littoral au cours des années 1990. À cette époque, les prospecteurs ont reconnu plusieurs gisements préhistoriques le long de cette même

*CEPAM - UMR 7264 CNRS/Université Nice Sophia Antipolis, Pôle Universitaire de Saint-Jean-d'Angély 3, 24 avenue des Diables-Bleus, 06357 NICE Cedex 4.

**Bénévole, Groupe de Recherches Archéologiques du Cotentin. 


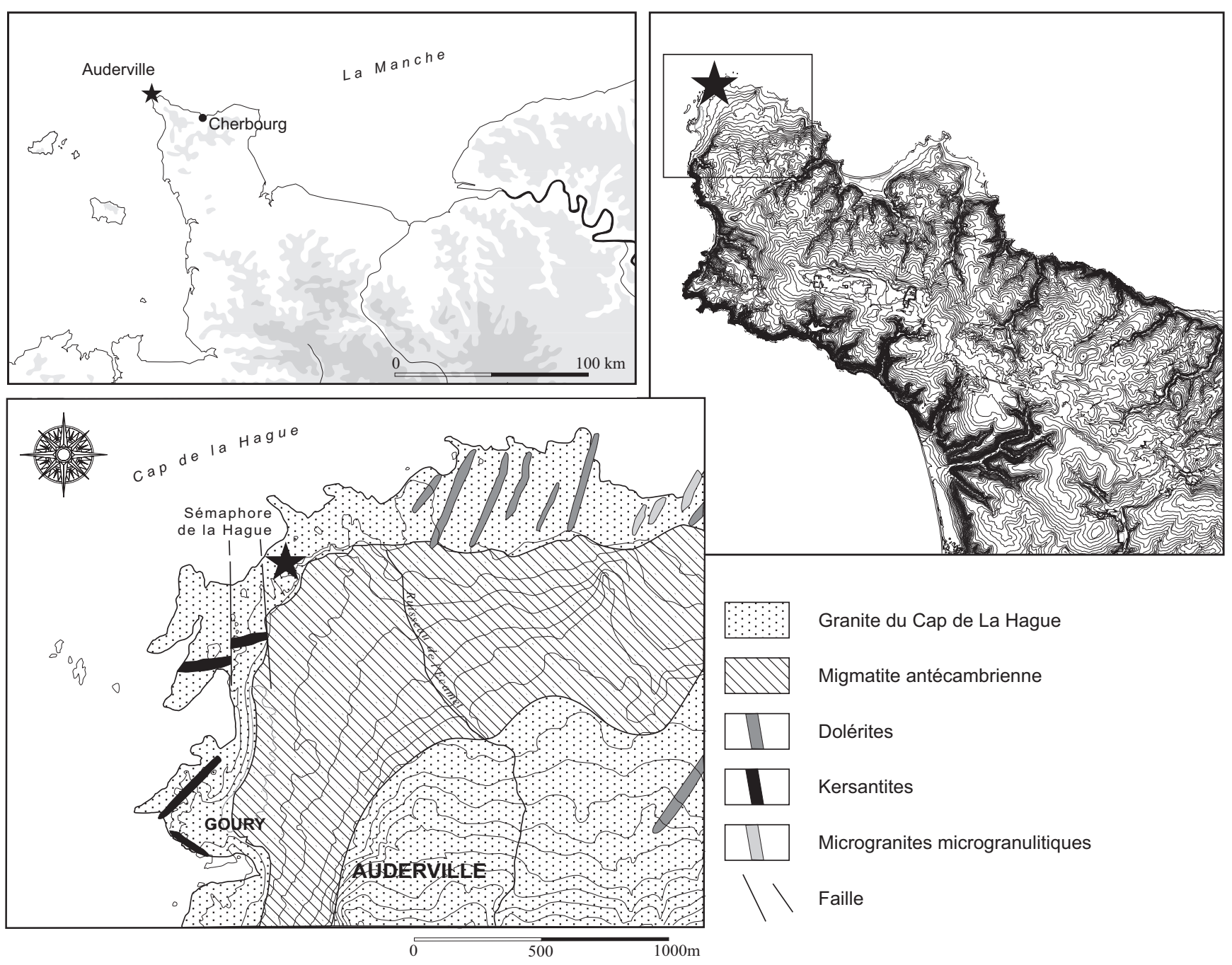

Figure 1 : Auderville "Le Sémaphore ". Localisation et cadre géologique du site.

Figure 1: Auderville "Le Sémaphore" - the site's situation and geographical environment.

côte. Leur surveillance régulière a mis en évidence une érosion particulièrement rapide du site, ce qui a motivé une intervention en 2006, dans le cadre du PCR sur La Hague dirigé par C. Marcigny (2009). Le sondage effectué a permis de sauvegarder les informations encore disponibles et de caractériser le mobilier découvert, dans la continuité des travaux réalisés dans le Cotentin (Ghesquière, 1995 et 1997; Juhel, 2006).

La coupe réalisée lors de la fouille montre une stratigraphie simple (fig. 2) : le substrat granitique (1) est surmonté d'un niveau argilo-limoneux brun induré stérile (2), puis d'un sédiment limono-sableux brun-jaune meuble contenant les vestiges archéologiques (3). Le dernier niveau (4), fortement anthropisé (foyer contemporain), est composé d'un sédiment meuble gris-noir, comportant de nombreuses esquilles de silex en position remaniée.
Ces niveaux stratigraphiques présentent une érosion en sifflet caractéristique. Le niveau contenant les vestiges (3) est tronqué au sommet par l'horizon 4, et par l'érosion au sud. Il est certain que ce niveau était originellement beaucoup plus étendu sur le promontoire. L'homogénéité des vestiges récoltés dans l'horizon 3 est probable; c'est sur ceux-ci que se fonde la description du mobilier

\section{LeS MatériaUX eT LE débitage}

Le mobilier est uniquement lithique. L'exploitation exclusive de galets littoraux selon un schéma opératoire simple a permis d'obtenir des éclats courts ou lamino-lamellaires. Le décompte des 2736 objets reconnus (tableau 1) montre la très large part détritique de cet ensemble, avec un total de 

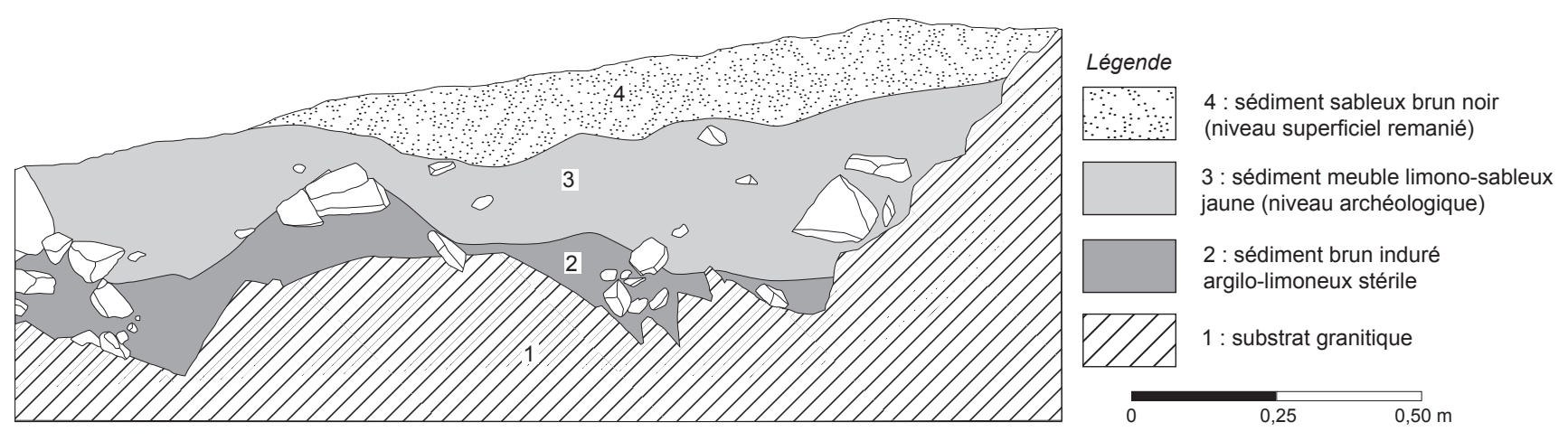

Figure 2 : Auderville «Le Sémaphore ». Stratigraphie du gisement.

Figure 2: Auderville "Le Sémaphore" - site stratigraphy.

2474 débris (90 \%). La quantité d'esquilles s'explique par le tamisage des déblais. Les objets observables d'un point de vue typo-technologique sont 234 déchets de taille et 28 outils.

\begin{tabular}{|l|c|}
\hline Éclat cortical (+50 \%) & 72 \\
\hline Éclat court & 84 \\
\hline Éclat lamino-lamellaire & 51 \\
\hline NL unidirectionnel & 5 \\
\hline NE multidirectionnel & 10 \\
\hline Fragment de nucléus & 12 \\
\hline TOTAL DÉCHETS DE TAILLE & 234 \\
\hline
\end{tabular}

\begin{tabular}{|l|c|}
\hline Débris, casson indéterminé & 77 \\
\hline Esquille & 2397 \\
\hline TOTAL DÉBRIS & 2474 \\
\hline
\end{tabular}

\begin{tabular}{|l|c|}
\hline Éclat denticulé & 7 \\
\hline Éclat retouché & 7 \\
\hline Bitroncature symétrique & 2 \\
\hline Lamelle à troncature concave & 1 \\
\hline Galet bouchardé & 11 \\
\hline TOTAL OUTILS & 28 \\
\hline TOTAL & 2736 \\
\hline
\end{tabular}

Tableau 1 : Décompte simplifié du mobilier lithique.

Table 1: Inventory of flint pieces.

On ne constate aucune complexité dans l'acquisition des matériaux : tous proviennent du cordon de galets local qui présente des petits rognons de qualités et de dimensions diverses. Si certains peuvent présenter une aptitude à la taille satisfaisante, on constate qu'aucune sélection n'a été opérée parmi ceux-ci. L'aspect extérieur des blocs bruts ne permet pas de deviner leur qualité interne. Ceux-ci ont tous été acheminés, puis testés et débités sur place. De même, aucune différence de traitement n'est perceptible parmi les déchets de taille récoltés. Ces données suggèrent un approvisionnement très local, qui exclut une attribution du site à une période antérieure au Mésolithique final, car le contexte littoral élimine toutes les périodes où la mer était plus distante.

Le débitage est conditionné par la piètre qualité et la petite taille des rognons, qui excluent toute chaîne opératoire complexe, récurrente ou standardisée. Aucun remontage n'a pu être mis en évidence parmi ces déchets de taille. Les produits obtenus sont également de dimensions et de morphologies variées; ils ne semblent régis par aucune norme de fabrication. La seule technique employée est la percussion directe dure. Aucun témoin de fracturation sur enclume n'a été observé. L'état d'abandon des nucléus montre que les blocs oblongs ont été utilisés pour produire des supports lamino-lamellaires selon un schéma opératoire unidirectionnel simple commencé dès l'entame. Des rognons plus sphériques ou moins réguliers ou qualitatifs sont employés pour un débitage d'éclats courts selon un schéma multidirectionnel simple. Rares sont les produits sans cortex, en raison de la petite taille de ces blocs.

\section{L'outillage}

L'outillage en silex se résume à 17 outils : il s'agit pour l'essentiel d'éclats retouchés (7) et denticulés (7) sans caractères particuliers. Deux petites bitroncatures (armatures tranchantes) ont également été récoltées (fig. $3, \mathrm{n}^{\text {os }} 1$ et 2 ). Elles sont de forme triangulaire et de petite taille. Une petite lamelle à troncature concave (fig. 3, no 3 ) a également été reconnue. La présence de ces outils expédients en petite quantité ne permet pas de déterminer une fonction particulière pour ce site. De plus, ces outils peuvent constituer un outillage produit sur place, mais non fonctionnel, voire abandonné car ne correspondant pas à l'intention de production du tailleur. Ce 

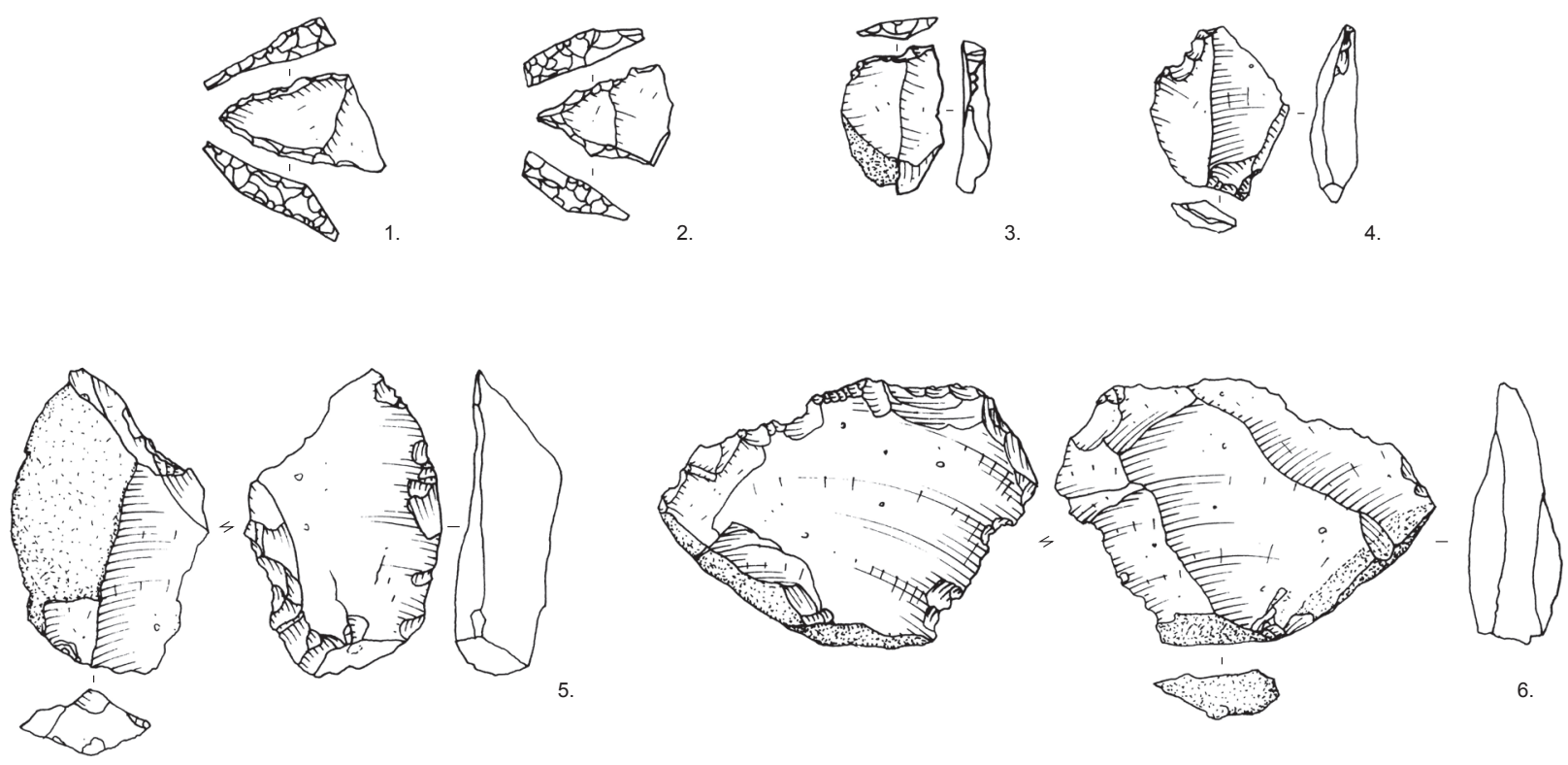

(1)
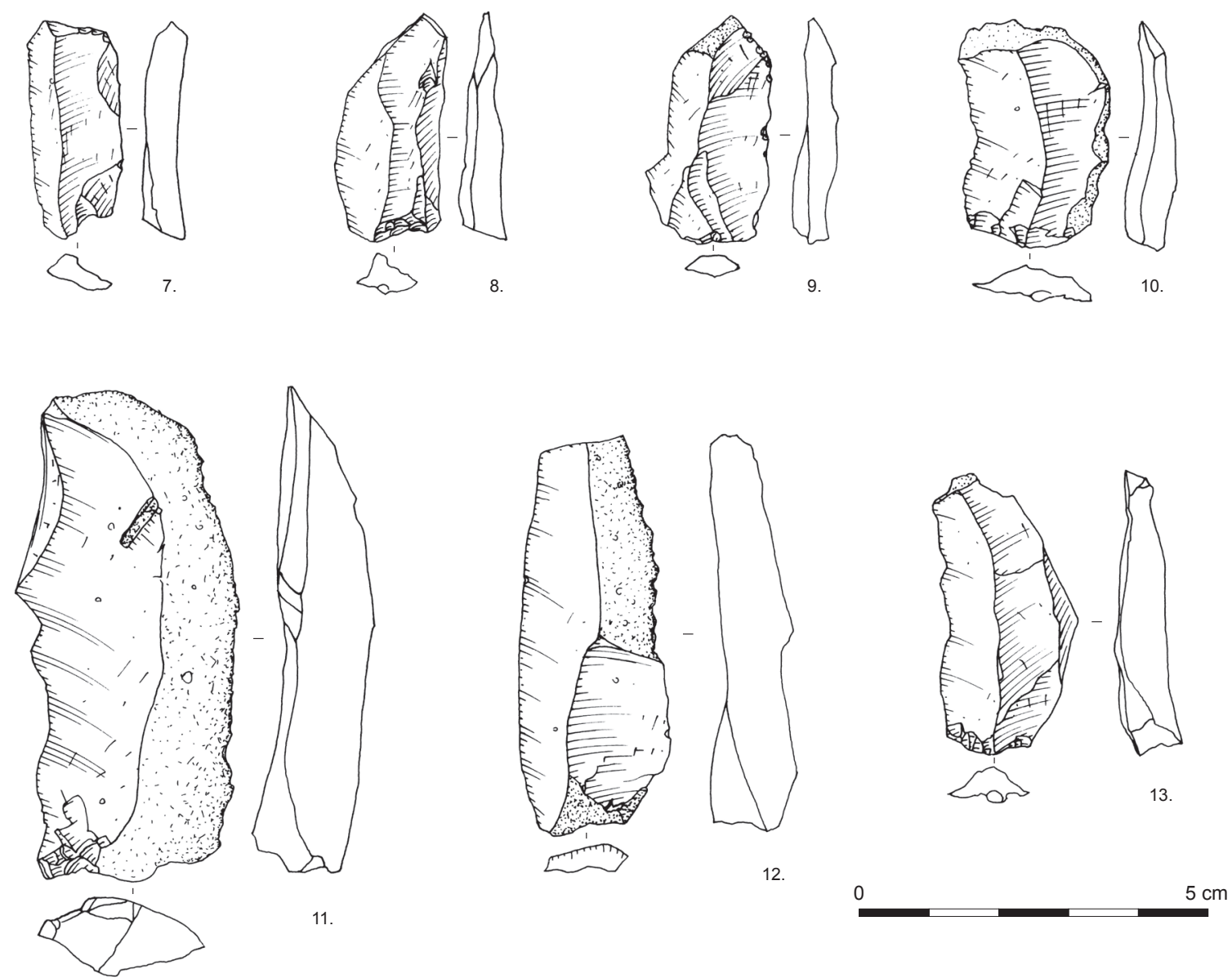

Figure 3 : Débitage et outillage : 1 et 2 : petites bi-troncatures (armatures tranchantes) ; $3:$ lamelle tronquée; 4 : éclat mince retouché; 5 : éclat épais retouché; 6 : éclat épais denticulé; 7 à 13 : produits lamino-lamellaires.

Figure 3: Débitage and tools: 1 and 2: small bitruncation; 3: truncated bladette; 4: fine retouched flake; 5: thick retouched flake; 6: denticulated flake; 7-13: laminated products. 

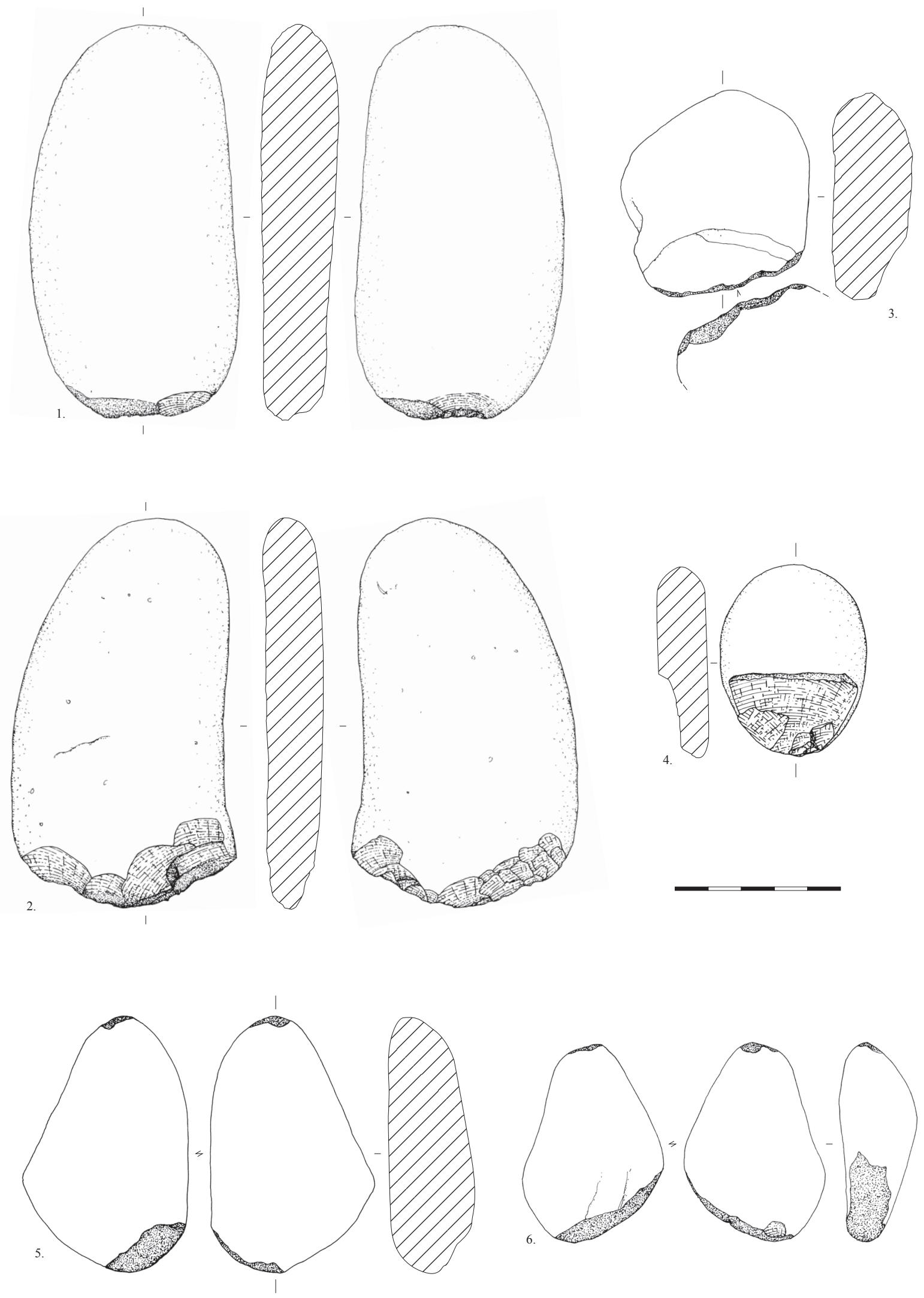

Figure 4 : Pièces bouchardées : 1 et 2 : plaquettes bouchardées; $3,4,5,6$ : galets bouchardés.

Figure 5: Pecked objects: 1 and 2: pecked plaquettes; 3-6: pecked pebbles. 
pourrait être notamment le cas des armatures de flèches, qui ne sont associées à aucun reste de faune.

En revanche, 11 galets en roches tenaces locales (grès et microgranite) présentent des stigmates de bouchardage liés à la taille de silex (fig. 4). Aucune usure en biseau, associable à d'autres activités (Juhel, 2006; Pailler, 2007) n'a été constatée. Parmi ces percuteurs, deux sont réalisés sur des plaquettes : des plaquettes de ce type ont été identifiés sur tous les sites attribués au Mésolithique moyen du groupe du Nord-Cotentin (Ghesquière, 1995; Ghesquière et al., 2000 ; Lefèvre, 1993).

\section{Conclusion}

En raison de l'importante érosion subie par ce site, le mobilier porté à l'étude est relativement réduit. Le débitage peu structuré exploite directement les galets du littoral pour produire des supports d'outils courts, ou allongés lorsque c'est possible. Il s'agit sans doute d'une installation temporaire, uniquement liée à la taille du silex, si l'on considère que les rares outils en silex ne sont pas significatifs d'une quelconque autre activité. Ce site documente toutefois les procédés d'acquisition et de transformation des ressources littorales. Plusieurs indices permettent de supposer une datation relativement récente :

- Le site a été découvert au sein d'un horizon holocène (postérieur à la mise en place des loess datés de la fin de la dernière glaciation : Cliquet et Lautridou, 2005).

- La position du site et les ressources exploitées supposent un contexte littoral, ce qui signifie que la mer était à un niveau proche de l'actuel.

- La nature des vestiges observés ne comprend aucun élément caractéristique du Mésolithique ancien ou moyen, ni du Néolithique.

- Les deux armatures découvertes présentent une typologie peu caractéristique, sans éléments de comparaison en Normandie (Ghesquière, 2012). Quelques éléments du Mésolithique final breton pourraient s'en rapprocher (Marchand, 1999; Pailler, 2007).

- Les plaquettes bouchardées ne trouvent également d'éléments de comparaison que dans des horizons du Mésolithique (Pailler, 2007; Ghesquière, 2012).

Ces quelques indices ne permettent aucune affirmation. L'attribution de cet amas de débitage côtier à la fin du Mésolithique est une proposition de travail et doit être considérée avec prudence, sous réserve d'éléments de comparaison plus pertinents.

\section{Remerciements}

SRA de Basse-Normandie, Gérard et Janine Vilgrain (GRAC), Cyril Damourette (Le Tourp), Emmanuel Ghesquière (Inrap), Cyril Marcigny (Inrap/PCR Hague).

\section{Bibliographie}

Cliquet D. et Lautridou J.-P., 2005 - Chronostratigraphie des formations du Pléistocène moyen et supérieur et sites associés en Normandie, BAR International Series 1364, Oxford, p. 53-62.

Dupret L., 2005 - Les pierres de La Hague, témoins de deux milliards d'années d'histoire de la Terre, in Marcigny C. et GHesquière E. (dir.), Archéologie, histoire et anthropologie de la presqu'île de La Hague (Manche). Analyse sur la longue durée d'un espace naturel et social cohérent. Première année de recherche, Beaumont-Hague, p. 13-18.

GHesquière E., 1995 - Étude préliminaire du site mésolithique d'Auderville - Roc de Gîte, Mémoire de diplôme de l'EHESS.

GHEsquière E., 1997 - Les galets et plaquettes du site mésolithique d'Auderville - Roc de Gîte, mémoire de DEA de l'université de Toulouse - Le Mirail, 213 p.

Ghesquière E., Lefevre P., Marcigny C. et Souffi B., 2000 - Le Mésolithique moyen du Nord-Cotentin, Basse-Normandie, France, BAR International Series 856, Oxford, 292 p.

Ghesquière E., 2012 - Le Mésolithique de Basse-Normandie, Thèse de doctorat de l'EHESS, Toulouse, 2 vol., 440 et 415 p.

Juhel L., 2006 - L'abri sous roche de la Jupinerie à Omonville-laPetite (Manche) et la question de l'implantation néolithique dans La Hague, mémoire de diplôme de l'EHESS, 134 p.

LefÈvre P., 1993 - Le site mésolithique de Flamanville (Manche). Étude typologique et approche technologique de l'industrie lithique, mémoire de maîtrise de l'université Paris I, 72 p.

Marchand G., 1999 - La néolithisation de l'Ouest de la France : caractérisation des industries lithiques, BAR International Series 748, Oxford, $486 \mathrm{p}$.

Marcigny C. (dir.), 2009 - Archéologie, histoire et anthropologie de la presqu'île de la Hague (Manche). Analyse sur la longue durée d'un espace naturel et social cohérent. Quatrième année de recherche, 2008, Beaumont-Hague, 152 p.

Pailler Y., 2007 - Des dernières industries à trapèzes à l'affirmation du Néolithique en Bretagne occidentale (5500-3500 av. J.-C.), BAR International Series 1648, Oxford, 340 p. 
Zusammenfassung: Auderville (Manche) „Le sémaphore“: ein lithisches Fundinventar mit bipolarer Abschlagstechnik aus dem Mesolithikum - Die Fundstelle von Auderville „Semaphore“ wurde 1990 bei Geländebegehungen durch G. und J. Vilgrain (GRAC) entdeckt. Sie wurde 2006 im Rahmen eines von C. Marcigny geleiteten Forschungsprojektes (PCR) zu La Hague ausgegraben, da sie akut durch die fortschreitende Erosion der Küstenlinie gefährdet war. Die Ausgrabung lieferte ein umfangreiches Fundinventar von Feuersteinabschlägen, insgesamt 2736 Fundstücke, die alle aus einem schmalen Bereich von rund $3 \mathrm{~m}^{2}$ stammen, der von der Erosion ausgespart geblieben war. Nur wenige Feuersteingeräte befanden sich im lithischen Fundgut. Das Flintschlagen erfolgte ausschließlich unter Nutzung der lokalen küstenbezogenen Flintvorkommen und zeigt nur eine geringe technologische Entwicklung. Die Fundstelle kann als ein temporär genutzter Werkplatz interpretiert werden, der die Ausbeutung der küstenbezogenen Flintvorkommen und ihre Nutzung veranschaulicht. Die Fundumstände sowie die technologischen Merkmale von vier Feuersteingeräten sprechen für eine Zuweisung der Fundstelle zum Mesolithikum.

Resumen: Auderville (Manche) "El Semáforo", un grupo de talla costero mesolítico - El sitio de Auderville "Semáforo" fue descubierto en 1990 durante las encuestas realizadas por G. y J. Vilgrain (GRAC). Fue excavado en 2006 en el marco del proyecto colectivo PCR La Hague PCR dirigido por C. Marcigny porque fue amenazado de destrucción a corto plazo (erosión costera). La operacion revelo un conjunto de talla de sílex costera de 2736 individuos, en una franja de tierra de tres metros cuadrados, guardada por la erosión. Pocas herramientas están presentes. La talla realizada en teja costera no es técnicamente invertido. Este sitio puede ser interpretado como un tamaño de la posición temporal. En él se documenta la adquisición y transformación de los recursos costeros. El contexto de descubrimiento, así como cuatro herramientas sugieren una atribución al Mesolítico.

Schlüsselwörter: Mesolithikum, Normandie, La Hague, Flintschlagen, bipolare Abschlagstechnik.

Palabras clave: Mesolítico, Normandía, Hague, talla costera. 